\title{
Purification and Characterization of Three Immunodominant Proteins (38, 30, and 16 kDa) of Mycobacterium tuberculosis
}

\author{
K. R. Uma Devi,* K. S. Senthil Kumar,* B. Ramalingam,* and Raja Alamelu*,1 \\ *Department of I mmunology, Tubercul osis Research Centre (ICMR), Mayor V. R. Ramanathan Road, \\ Chetput, Chennai-600 031, India
}

Received J une 26, 2001; and in revised form October 10, 2001

Specific mycobacterial antigens are an important prerequisite in the serodiagnosis of tuberculosis. Many studies have reported the use of both native and recombinant proteins. Even though recombinant proteins can form standardized reagents with unlimited supply, their diagnostic test characteristics were not satisfactory in some cases. In this study we have purified the 38-, 30- (antigen 85B), and 16-kDa native antigens of Mycobacterium tuberculosis by procedures with limited number of steps. Starting with the secreted antigens of $M$. tuberculosis H37Rv, the 38-kDa form was purified by preparative isoelectric focusing, followed by preparative electrophoresis. Separation of antigen 85 components was achieved by anion-exchange chromatography, followed by hydrophobic interaction chromatography. Gel-permeation chromatography was employed for the isolation of the 16-kDa form, from the cytosol fraction of M. tuberculosis H37Rv. By using a minimal number of steps, considerable yields of these proteins were obtained without loss of immunological activity. The native proteins purified were characterized by analytical two-dimensional electrophoresis, HPLC, and circular dichroism studies. Conformation of the native 38-kDa form purified in our laboratory was different from that of the recombinant 38-kDa form from the WHO Bank. The identities of these native antigens were established by immunoblotting with known monoclonal antibodies from the WHO Bank. (๑) 2002 EIsevier Science (USA)

\footnotetext{
${ }^{1}$ To whom correspondence and reprint requests should be addressed. Fax:+91 (044) 826 2137. E-mail: trcicmr@md3.vsnl.net.in (mdp4ar), alameluraja@yahoo.com.
}

The global incidence of tuberculosis (TB) was estimated to have been 8-10 million cases, causing approximately 3 million deaths per year, more than that from any other single infectious disease (1). This contagious disease has an increased incidence in recent years mainly due to its association with HIV (2) and also due to the occurrence of multi-drug-resistant strains (3). All these point to the need for a rapid, simple, and effective method of case finding.

Serodiagnosis of tuberculosis using enzyme-linked immunosorbent assay (ELISA) has been attempted in earlier days by using crude and semipurified antigens and were found to give a varying range of sensitivity and specificity $(4,5)$. The results underline the importance of identifying the species-specific antigens and using them for diagnosis. Several studies havereported using recombinant mycobacterial antigens in serodiagnosis, in order to avoid thetedious procedures of conventional purification. However, recombinant proteins had their own limitations, such as lack of glycosylation, less satisfactory performance in diagnostic assays, etc.

In the present study, two actively secreted antigens (38 and $30 \mathrm{kDa}$ ) and one cytosolic antigen (16 kDa) of M. tuberculosis were isolated for evaluation in ELISA. One of the secreted antigens, $38 \mathrm{kDa}$, has been reported to be restricted in its distribution to the M. tuberculosis complex and found to be specific in immunoassays. The 30-kDa antigen, which forms part of the antigen 85 complex, is an early and predominant antigen. Hence, it is a suitable candidate for early diagnosis. In our earlier immunoblots with tuberculous and normal sera, an antigenic band of $\sim 16-17 \mathrm{kDa}$ was observed to specifically react with the tuberculous sera and not with normal sera. Later, this antigen was found to be similar 
to the $\alpha$-crystallin homologue of small heat shock proteins, which is associated with stationary phase.

\section{MATERIALS AND METHODS}

Antigen

Preparation of H37Rv culture filtrate antigen (CFA) M. tuberculosis H37Rv was grown in Sauton's liquid medium for 6 weeks as a surface pellicle. Bacilli were removed by centrifugation and the culture supernatant was filtered through a Seitz filter. Proteins in the culture filtrate were precipitated with $90 \%$ saturated ammonium sulfate. Thefinal precipitate was dissolved and dialyzed extensively against phosphate-buffered saline (PBS), 0.1 M, pH 7.2. The antigen was aliquoted and stored at $-70^{\circ} \mathrm{C}$ in the presence of sodium azide and the protease inhibitor phenylmethylsulfonyl fluoride (PMSF).

Preparation of cytosol antigen. The cytosol antigen was prepared from $M$. tuberculosis H37Rv bacilli grown for 6 weeks in Sauton's liquid medium. One hundred milliliters of the packed volume of the bacilli was treated with twice the volume of breaking buffer consisting of $20 \mathrm{mM}$ Tris, $8.5 \%(\mathrm{w} / \mathrm{v}) \mathrm{NaCl}$ al ong with protease inhibitors [leupeptin, pepstatin A, PMSF, ethylenediaminetetraacetic acid (EDTA), ethylene glycol-bis $\beta$ aminoethyl ether) tetraacetic acid (EGTA), N-tosyl-Lphenylalanine chloromethyl ketone (TPCK) (1 mM each), dithiothreitol (DTT), and $\mathrm{N}$ - $\alpha$-p-tosyl-L-lysine chloromethyl ketone (TLCK) (100 $\mu \mathrm{M})$ (Sigma Chemical Co., U.S.A.)]. The final $\mathrm{pH}$ was adjusted to $\mathrm{pH} 7.4$. To the buffer, RNAse and DNAse were also added in addition to sodium azide and Tween 80 . The bacterial cells in the breaking buffer were disrupted by subjecting them to sonication for 30 cycles, each cycle lasting for $1 \mathrm{~min}$ with a cooling interval of $1 \mathrm{~min}$.

The sonicate was then centrifuged at $10,000 \mathrm{rpm}$ for $10 \mathrm{~min}$ at $4^{\circ} \mathrm{C}$. The pellet contained the cell wall material while the supernatant had the cytosol proteins along with the cell membrane. Ultracentrifugation of the supernatant at 45,000 rpm for $1 \mathrm{~h}$ resulted in pelleting of the cell membrane and the cytosol remained in the supernatant.

Purification of the 38-kDa antigen. The 38-kDa antigen was purified by two-dimensional preparative electrophoresis.

The Rotophor preparatory IEF cell (Bio-Rad Laboratories, U.S.A.) was used for the first-dimensional separation of proteins based on the differences in their isoelectric points ( $\mathrm{pl}$ ). Whole M. tuberculosis H37Rv CFA (100 mg) was first dialyzed overnight against distilled water. Following dialysis, $4 \mathrm{M}$ urea, $0.2 \%$ digitonin, $0.2 \%$ Chaps, $10 \%$ glycerol, and $1 \%$ carrier ampholytes ( $\mathrm{pH}$ range 4- 6:3-10 = 4:1) (Bio-Rad Laboratories) were added and the final volume was brought to $55 \mathrm{ml}$ with distilled water.
The sample was loaded into the Rotophor cell and focusing was carried out at $12 \mathrm{~W}$ constant power for 4-5 h, with cooling. The initial power conditions were $500 \mathrm{~V}$ and $20 \mathrm{~mA}$. At equilibration, the conditions were $1200 \mathrm{~V}$ and $10 \mathrm{~mA}$. Twenty fractions of $2.5 \mathrm{ml}$ each were collected, their pH was measured, and their polypeptide composition was analyzed by a sodium dodecyl sulfatepolyacrylamide gel electrophoresis (SDS-PAGE) gel.

Model 491 Prep Cell (Bio-Rad Laboratories) was used for continuous-elution electrophoresis. Rotophor fractions containing 38-kDa antigens were pooled and dialyzed extensively against distilled water at $4^{\circ} \mathrm{C}$. The proteins concentrated up to $2.5 \mathrm{ml}$ were dissolved in $0.5 \mathrm{ml}$ of $6 \times$ SDS sample buffer and applied to the PrepCell. A $10 \%$ resolving gel $(6.0 \mathrm{~cm}$ in height) and $4 \%$ stacking gel $(1.5 \mathrm{~cm}$ in height) were used for the run. Tris-glycine-SDS (25- 192 mM, 0.1\%) was used as running buffer and PBS as elution buffer. The gel was subjected to $12 \mathrm{~W}$ constant power. The run was carried out for $8 \mathrm{~h}$.

After elution of bromphenol blue tracking dye, fractions were collected at a rate of $1.5 \mathrm{ml} / \mathrm{min}$. The pol ypeptide composition of every 10th fraction was analyzed by SDS-PAGE. When the region with the protein of interest was identified, every fraction within that region was analyzed to determine the level of contamination. Fractions containing the purified 38-kDa antigen were pooled and concentrated by lyophilization.

Purification of the Ag85 complex. CFA (25 mg) was separated into multiple fractions by passage through a prepacked anion-exchange column $(10 \times 11 \mathrm{~cm})$ of QAE - Sepharose. Tris- $\mathrm{HCl}, 0.05 \mathrm{M}$, pH 8.1 buffer was used as the starting buffer. A gradient of $0-1 \mathrm{M} \mathrm{NaCl}$ in the same buffer was used for elution. The run was carried out in the high-performance liquid chromatography (HPLC) system (Millenium v2.00, Waters, U.S.A.). The eluted fractions were analyzed in SDSPAGE and the Ag85 complex-containing fractions were pooled.

F urther purification of the A, B, and C components from the Ag85 complex was done by passing it through the hydrophobic interaction chromatography (HIC) column, namely the phenyl-Sepharose HP column $(3.5 \times$ $1 \mathrm{~cm}$ ) (Amersham-Pharmacia Biotech, Sweden). Three different buffers were used during the run. They are as follows: Buffer $\mathrm{A}, 0.01 \mathrm{M} \mathrm{NaH}_{2} \mathrm{PO}_{4}, \mathrm{pH} 6.8$, for washing; Buffer $\mathrm{B}, 0.01 \mathrm{M}$ Tris-glycine, $\mathrm{pH}$ 8.9, for binding; and Buffer C, $0.01 \mathrm{M}$ Tris-glycine with $50 \%$ ethylene glycol, $\mathrm{pH}$ 8.9, for gradient elution. The eluted proteins were collected as 1-ml fractions and analyzed on SDS-PAGE to identify the fractions containing antigens 85A, B, and $\mathrm{C}$.

Antigen 6 (old nomenclature for Ag85 B) and recombinant $85 \mathrm{C}$ were kind gifts from Professor Thomas Daniel (Cleveland, $\mathrm{OH}$ ) and Professor Patrick Brennan (Fort 
Collins, (C), respectively. These were used as reference antigens for characterizing the protein isolated in our laboratory.

Purification of the 16-kDa antigen. The cytosol fraction of the sonicate antigen of $M$. tuberculosis H37Rv (150 mg in $1.5 \mathrm{ml}$ ) was passed through a gel-filtration chromatography column of Ultrogel ACA34 $(75 \times 5 \mathrm{~cm})$ (Pharmacia, Sweden). The cytosol fraction was loaded into the gel-filtration column along with bromphenol blue and blue dextran to serve as indicators for the mobility of samples. Elution was carried out with 20 $\mathrm{mM}$ Tris- $\mathrm{HCl}$ buffer al ong with EDTA, $1 \mathrm{mM}$ DTT, and $0.5 \mathrm{M} \mathrm{NaCl}$, at pH 8.2. The cytosol antigens separated by Ultrogel ACA34 were collected as 1-ml fractions at a rate of $0.75 \mathrm{ml} / \mathrm{min}$. A total of 350 fractions were collected.

The protein concentrations of the CFA and fractions were estimated by the BCA kit (Pierce, U.S.A.).

\section{Analytical SDS-PAGE}

CFA and fractions were analyzed by SDS-PAGE performed in slab gels by the method of Laemmli (6). A $12.5 \%$ acrylamide- bisacrylamide gel with $0.4 \%$ SDS in $0.375 \mathrm{M}$ Tris- $\mathrm{HCl}, \mathrm{pH} 8.8$, was used to separate the antigens. The stacking gel was $4 \%$ acrylamidebisacrylamide with $0.4 \%$ SDS in $0.125 \mathrm{M}$ Tris- $\mathrm{HCl}, \mathrm{pH}$ 6.8. Gel thickness was $1.5 \mathrm{~mm}$. The samples (usually $50 \mu \mathrm{g}$ of $\mathrm{Ag} / \mathrm{cm}$ length of the gel) were applied under reducing conditions by heating the samples in sample buffer for $5 \mathrm{~min}$ at $96^{\circ} \mathrm{C}$. Gels were run in a vertical slab gel apparatus (Bio-Rad Laboratories).

After el ectrophoresis, the gels werestained with $0.2 \%$ Coomassie brilliant blue for $1 \mathrm{~h}$ at room temperature with shaking and destained by successive changes of destainer consisting of $45 \%$ methanol and $10 \%$ acetic acid until the background became clear.

\section{Immunoblotting}

Resolved antigens were electrophoretically transferred to NCP $(0.45-\mu \mathrm{m}$ pore size) by the method of Towbin et al. (7), using a transblot apparatus (Bio-Rad Laboratories). The gels were soaked in transfer buffer $(0.025 \mathrm{M}$ Tris, $\mathrm{pH} 8.3$, containing $0.192 \mathrm{M}$ glycine and $20 \%$ methanol) for $30 \mathrm{~min}$ and transfer was carried out at $0.65 \mathrm{~A}$ for $1 \mathrm{~h}$. The strips were incubated overnight at $4^{\circ} \mathrm{C}$ with the appropriate dilutions of polyclonal and monoclonal antibodies. After washing with PBST, the strips were probed with anti-mouse/rabbit Ig peroxidase conjugate for $1 \mathrm{~h}$ at $37^{\circ} \mathrm{C}$. The reaction was visualized by incubating the strips with 3,3'-diamino benzidine (DAB) (Sigma Chemical Co., U.S.A.).

\section{Analytical 2-D Electrophoresis}

The method of O'F arrell, with modification, was followed (8). For the first-dimension separation, isoel ectric focusing was performed using a vertical mini-IEF system (Hoeffer Scientific, U.S.A.) and the second-dimension separation was carried out using analytical SDSPAGE. One hundred micrograms of purified 38-kDa or Ag85 protein was mixed with $30 \mu$ l of IEF sample buffer [9 M urea, $2 \%$ Nonidet P-40, 5\% $\beta$-mercaptoethanol, 310 ampholyte (Pharmacia)] and denatured by incubation overnight at $4^{\circ} \mathrm{C}$. The sample was then filtered using the Micropure filtration units (Amicon, U.S.A.). It was applied to $1.5-\mathrm{mm}$-i.d. $\times 7$-cm-long capillary tube gels after prefocusing the gels for $30 \mathrm{~min}$ at $250 \mathrm{~V}$. The protein was focused for $5 \mathrm{~h}$ at a constant voltage of 500 V, with $10 \mathrm{mM} \mathrm{H}_{3} \mathrm{PO}_{4}$ and $20 \mathrm{mM} \mathrm{NaOH}$ as anolyte and catholyte, respectively. Thegels were then extruded out of the capillary tube, immersed in equilibration buffer for 30 min with five changes, and placed on the SDS-PAGE gel of $12.5 \%$ resolving gel and $4 \%$ stack gel. Electrophoresis in the second dimension was carried out at $120 \mathrm{~V}$ at constant power until the dye front reached the bottom of the gel. The proteins were visualized after silver staining (Bio-Rad Laboratories).

\section{Reverse-Phase HPLC}

The purified 16-kDa protein from the gel-filtration column was analyzed by HPLC. The protein was dialyzed in $50 \mathrm{mM}$ Hepes buffer (Biofluids, U.S.A.) and concentrated by lyophilization in a SpeedVac (Savant, U.S.A.). Ten micrograms $(250 \mu \mathrm{l})$ of the concentrated sample was passed through a reverse-phase C18 column $(22 \times 0.5 \mathrm{~cm})$ (Merck, Germany). Elution was carried out with an isocratic flow of $30 \%$ acetonitrile, at a flow rate of $0.2 \mathrm{ml} / \mathrm{min}$, and the eluted fractions $(0.2$ $\mathrm{ml} /$ fraction) were analyzed by SDS-PAGE.

\section{Circular Dichroism (CD) Studies}

CD measurement was carried out on a spectropolarometer (J ASCO-715, J apan) using a 0.1-cm cell at $0.2-\mathrm{nm}$ intervals with three scans averaged for each. CD spectra were recorded in the 200- to 250-nm range. The mean residue ellipticity, $[\theta]$, is given in units of deg. $\mathrm{cm}^{2} . \mathrm{dmol}^{-1}$. CD spectra were recorded for purified 38- and 16-kDa proteins $\left(1 \times 10^{-5} \mathrm{M}\right)$ at $\mathrm{pH}$ 7.0.

\section{RESULTS}

\section{Purification of the 38-kDa Antigen}

The CFA proteins were separated into 20 fractions based on their isoelectric points (pl) (Fig. 1). It was observed that the proteins had a limited spread in their $\mathrm{pl}$, namely from pH 4.0 to 6.0. Because of their close $\mathrm{pl}$ values, proteins could not be separated very well in the first dimension. Fractions rich in $38-\mathrm{kDa}$ antigen were pooled together and separated on preparative SDS-PAGE. From $100 \mathrm{mg}$ of the starting material 


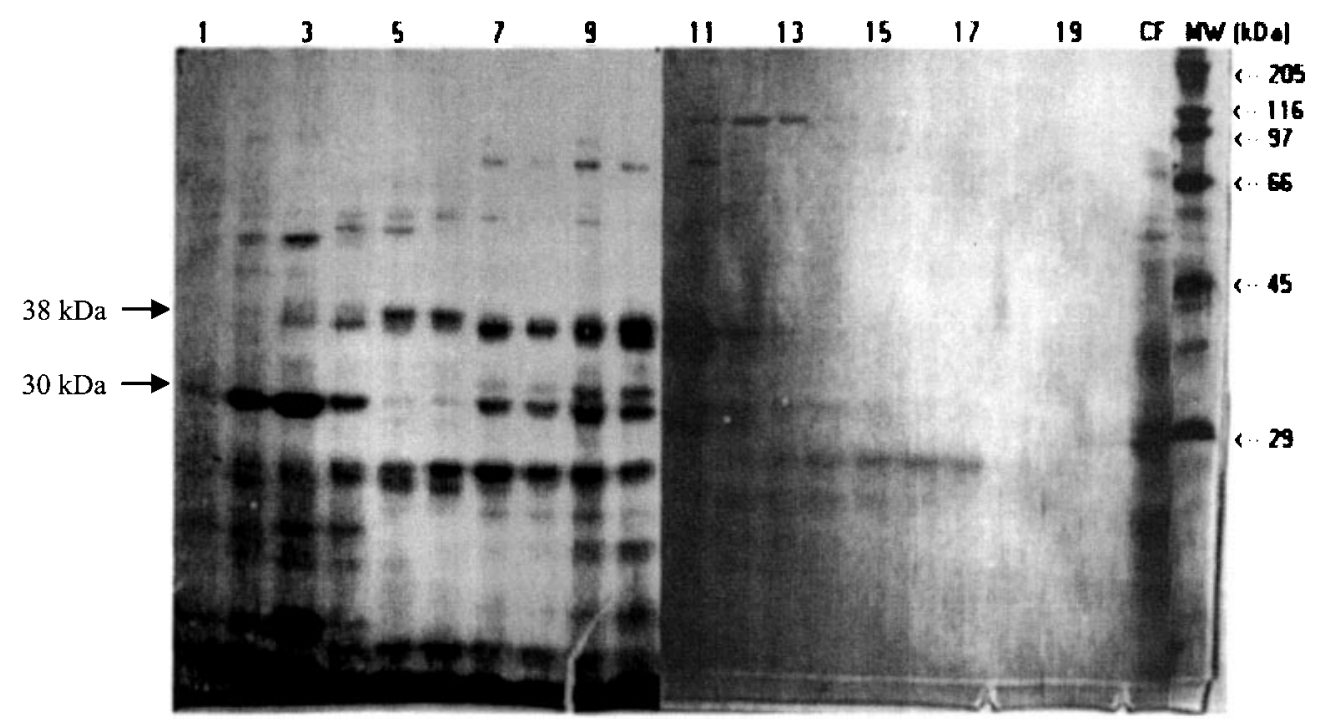

FIG. 1. Fractionation of H37Rv CFA by preparatory IEF. Lanes 1-20, fraction Nos. 1-20; CF, culture filtrate antigen; MW (kDa), molecular weight markers. The CFA and fractions were run on $12.5 \%$ SDS-PAGE and stained with $0.2 \%$ Coomassie brilliant blue. The positions of 38 and $30 \mathrm{kDa}$ have been marked.

(CFA), approximately $3 \mathrm{mg}$ of purified 38-kDa antigen was recovered.

To characterize the isolated protein, it was run on a 2-D gel, with ampholytes at a pH gradient of 4-6. The single band of $38 \mathrm{kDa}$ seen in 1-D resolved into three spots of very close pl values in the range of pH 5.0. To establish the identity of the antigen, it was immunoblotted with monoclonal antibody (MAb) IT-23 from the WHO Bank and a polyclonal antiserum against H37Rv CFA. Recognition of the purified antigen with the reference $\mathrm{MAb}$ confirms its similarity to the $38-\mathrm{kDa}$ antigen reported earlier.

The circular dichroism spectrum of the 38-kDa form, purified in this study, demonstrated a characteristic $\beta$ sheet (peak absorption at $212 \mathrm{~nm}$ ). Thus, the molecular conformation (and hence the B-cell epitopes) differed compared to the conformation of the r38-kDa form from the WHO Bank [predominant $\alpha$-helix, peaks at 208 and $222 \mathrm{~nm}$ (Fig. 2)].

\section{Purification of the Ag85B (30 kDa) Antigen}

The antigen 85 complex isolated by anion-exchange chromatography was analyzed by 2-D gel el ectrophoresis, with ampholytes at a pH gradient of 4-6. Three spots in the pl region of 4.0-4.5 were seen corresponding to antigens $85 \mathrm{~A}, 85 \mathrm{~B}$, and $85 \mathrm{C}$ (Fig. 3). Further preparatory separation of the complex into individual components, antigens 85A, 85B, and 85C, was made possible by HIC. From $25 \mathrm{mg}$ of the starting material (CFA), approximately $360 \mu \mathrm{g}$ of purified 30-kDa antigen was recovered.

The purified 30-kDa antigen was blotted and probed with MAbs from the WHO Bank. Three MAbs, IT-27,
IT-44, and IT-49, that specifically react with the 30-I 31-kDa form, recognized the purified protein.

\section{Purification of the 16-kDa Antigen}

The SDS-PAGE analysis of the purified 16-kDa protein from the cytosol, al ong with the other two purified antigens, is shown in Fig 4 . From $150 \mathrm{mg}$ of the starting material (cytosol), approximately $3 \mathrm{mg}$ of purified 16kDa protein was recovered.

Theprotein purified by gel-filtration chromatography was subjected to reverse-phase HPLC in order to ascertain the purity of the protein. The protein eluted at retention times (RT) of 9 and $13 \mathrm{~min}$. The individual fractions obtained at the two time points were analyzed on SDS-PAGE. The peak obtained at a RT of 9 min showed a protein at the 16-kDa region while the peak at $13 \mathrm{~min}$ was found to contain a band at the $16-\mathrm{kDa}$ region, as well as at the 32-kDa region (Fig. 5). Thus, the 16-kDa form exists as monomer and multimer, as reported in the literature.

Figure 5 also shows multiplesmall peaks, in addition to the major peaks. All eluted fractions were concentrated and tested. Except for the peak at 9 min (and the shoulder) and peak at $13 \mathrm{~min}$, which are marked, the other fractions did not show any bands.

The circular dichroism spectrum was determined for the purified protein and showed a maximum peak at $214 \mathrm{~nm}$ with a molar ellipticity of $-65,780 \mathrm{deg} . \mathrm{cm}^{2}$. $\mathrm{dmol}^{-1}$, characteristic of a $\beta$-sheet structure (Fig. 6).

The identity of the purified 16-kDa antigen was established by an immunoblot with MAbs IT-1 and IT-4 
a.

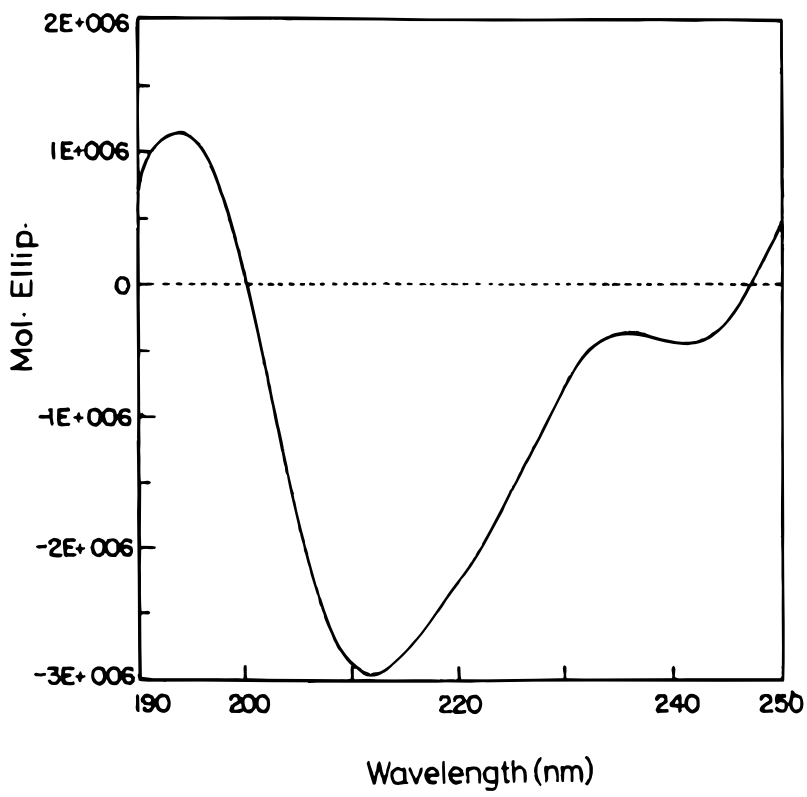

b.

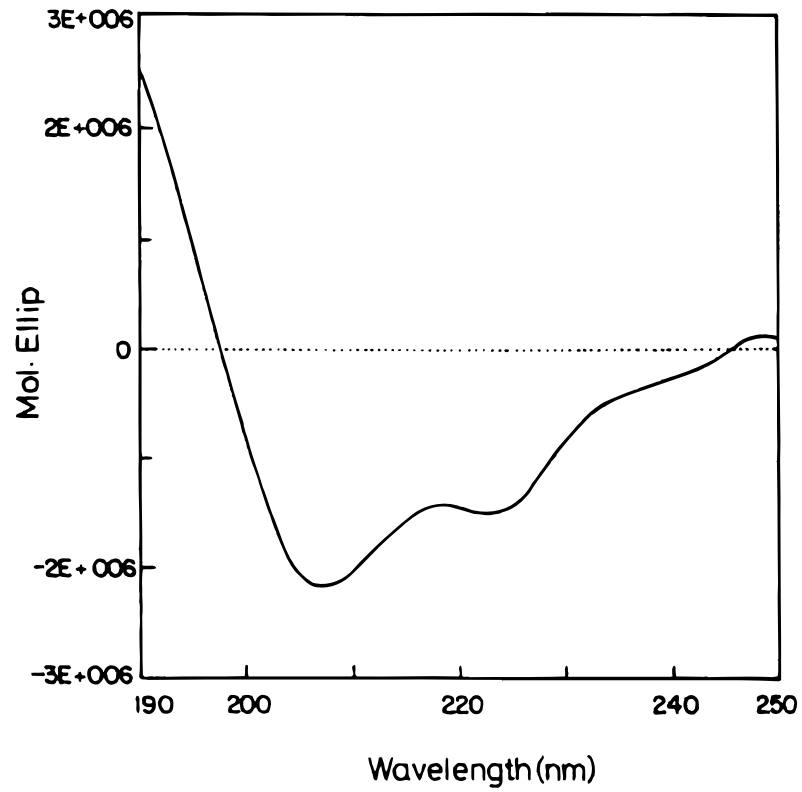

FIG. 2. Circular dichroism spectrum of the 38-kDa protein. (a) Purified native 38-kDa protein. (b) Recombinant 38-kDa protein. Protein concentration was adjusted to $1 \times 10^{-5} \mathrm{M}$ at pH 7.0 and scanned at the 200- to $250-\mathrm{nm}$ range.

and polyclonal antibody against H37Rv as positive control. A positivereaction with the established MAbs suggests the identity of this protein with the already reported 16-kDa antigen.

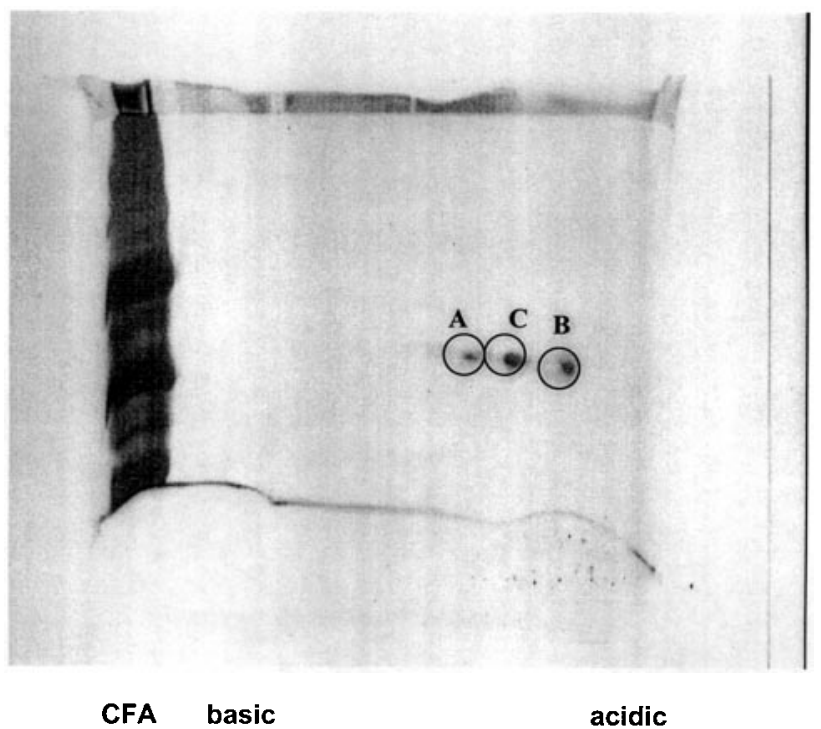

FIG. 3. Two-dimensional separation of antigen 85 complex. CFA, culture filtrate antigen. CFA was resolved first in a $\mathrm{pH}$ gradient of 4- 6 (one-dimensional IEF) and then on a $12.5 \%$ gel (two-dimensional SDS-PAGE). The gel was stained with silver stain. The three spots corresponding with Ag85 (A, B, and C) have been marked.

\section{DISCUSSION}

Research for identification of a suitable antigen for serodiagnosis of tuberculosis has come a long way and yet there is much more to be explored. In this study, three antigens have been isolated from the virulent strain of M. tubercul osis to be evaluated in various categories of patients and normal sera.

The 38-kDa antigen was originally purified by affinity chromatography using a polyclonal antibody (9) and later using a MAb $(10,11)$. Espitia and colleagues (12)

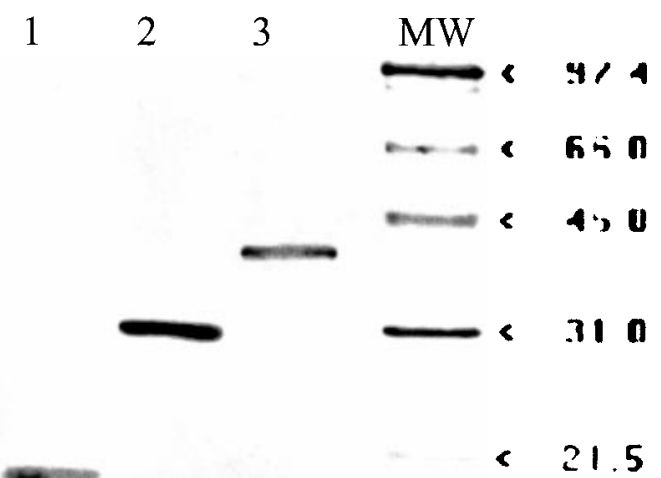

FIG. 4. Purified proteins of $M$. tuberculosis. Lane $1,16 \mathrm{kDa}$; lane 2, $30 \mathrm{kDa}$; lane 3, $38 \mathrm{kDa}$; MW, molecular weight markers. The gel was stained with $0.2 \%$ Coomassie brilliant blue. 


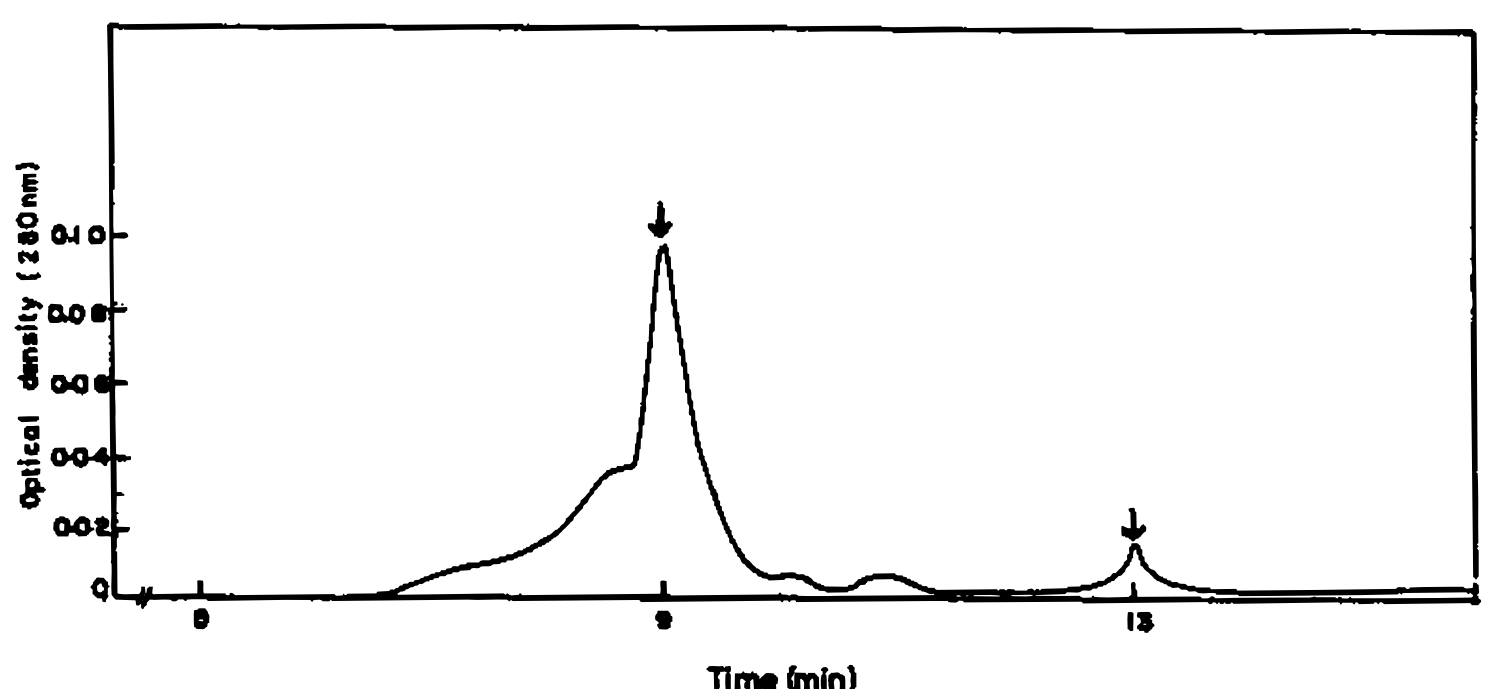

FIG. 5. Reverse-phase HPLC of the purified $16-k D a$ protein. Ten micrograms ( $250 \mu l)$ of the concentrated sample was passed through a reverse-phase C18 column. Each eluted fraction $(0.2 \mathrm{ml} /$ fraction) was analyzed by SDS-PAGE. Arrows indicate the only two fractions showing a band on SDS-PAGE.

eluted the protein with acetonitrile after transferring CFA to the nitrocellulose membrane. Later, attempts at cloning and sequencing the gene coding for this antigen offered the potential for greater availability of this protein (13). In the present study, two-dimensional preparative electrophoresis, based on the combination of isoelectric focusing and preparatory electrophoresis, all owed the complete purification of the 38-kDa antigen from whole bacterial culture filtrate in only two steps.

The isolated 38-kDa form shows three spots in 2-D, with close $\mathrm{pl}$ values in the $\mathrm{pH} 5.0$ region. These are different isoforms of the same molecule. The 38-kDa antigen has been shown to resolve to multiple spots. Bassey et al. (14) have demonstrated that there are at least three reactive antigens in 2-D blots of $M$. tuberculosis soluble extract (MTSE) in the 38-kDa region.

The 38-kDa form isolated by different methods has been used in diagnostictests, mainly ELISA, with varying outcomes. We have obtained preliminary data, using our 38-kDa form. The interesting finding is that the 38-kDa form purified during this study was equally sensitive in sputum smear-positive and smear-negative cases ( $\sim 60 \%$ ) (data not shown). The difference between these results and the lower sensitivity results reported by others $(15 \%)(15,16)$ can be explained, perhaps, on the basis of the mode of preparation of antigen. Folding of proteins is very important in maintaining the conformation of the molecule, which the antibodies recognize, and it is influenced by the method of isolation of the antigen. Our preparation perhaps differs from the affinity-purified and recombinant antigens in its 3-D fol ding, as evidenced by the CD spectrum.

Another antigen isolated and used in this study is the $30-k D a$ antigen of the Ag85 complex. This complex consists of at least three distinct, but related, proteins as shown by cross-immunoelectrophoresis and are designated as 85A, 85B , and 85C with approximate molecular masses of 31, 30, and $31.5 \mathrm{kDa}$, respectively (17-19). This antigen has been variably cited in the literature as a2, $\alpha$-antigen, fibronectin binding protein, antigen 6, Ag85 complex, etc. (19).

Various investigators have used different combinations of column chromatography methods for the purification of antigen 85 complex. I on-exchange chromatography provided substantial purification of a2 antigen in the hands of Daniel and Ferguson (20). Since then, DEAE - cellulose ion-exchange chromatography, either alone or in combination with another chromatography method, was used for the purification of 30- to 31-kDa antigens by many investigators $(19,21)$. Separation of individual components has been reported only on an analytical scale (22).

In our study, the initial QAE-Sepharose-purified fraction showed three spots in the pl region of 4.0-4.5, corresponding to antigens $85 \mathrm{~A}, 85 \mathrm{~B}$, and $85 \mathrm{C}$, similar tothat demonstrated by others $(17,22,23)$. Thesimilarity of our 30-/31-kDa form to the Ag85 components was established by immunoblot recognition with reference MAbs IT-27, IT-44, and IT-49. The three-member complex was further separated by HIC on phenyl-Sepharose. Our preliminary studies show that of the three components, Ag85B (30 kDa) was the most useful for diagnosis (data not shown).

The 16-kDa protein bel ongs to the $\alpha$-crystall in superfamily of small heat shock proteins and has been variably referred to as sHsp16, Hsp.16.3, Acr, and MPT63. This is similar to the major membrane protein (24) and Nox16 (25) referred to earlier. 


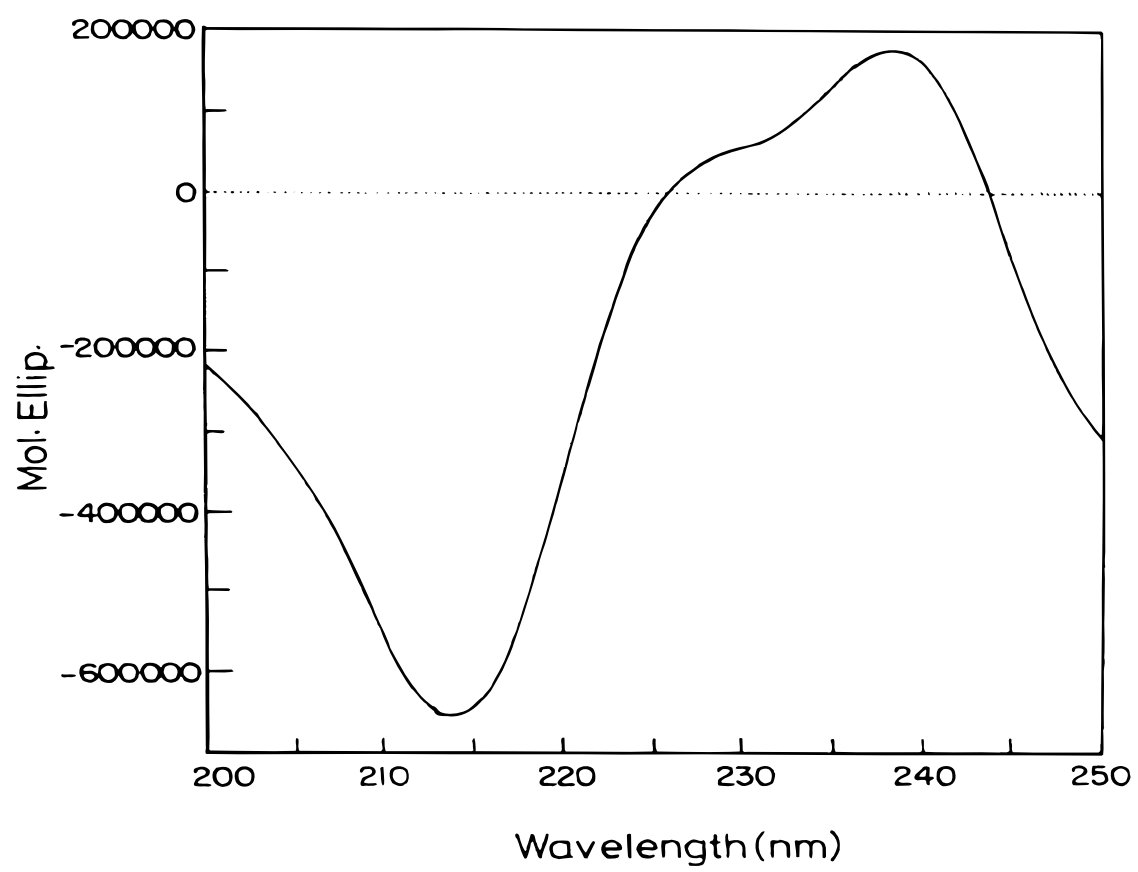

FIG. 6. Circular dichroism spectrum of the purified 16-kDa protein. Protein concentration was adjusted to $1 \times 10^{-5} \mathrm{M}$ at $\mathrm{pH} 7.0$ and scanned at the 200 - to $250-$ nm range.

Earlier investigators have used affinity purification procedures for the purification of 16-kDa antigen (15), while Verbon et al. (26) used the molecular sieving chromatography procedure. The antigen described in this study, isolated from the cytosol fraction, has been assigned a mass of $16 \mathrm{kDa}$ based on its movement in SDS-PAGE. Further evidence for confirmation of the identity of this protein with earlier reported Hsp.16.3 comes from study on the circular dichroism of this native protein. Our purified protein has been assigned a predominantly $\beta$-sheet structure with a peak in the 210- to 215-nm region, which is in accordance with the report of Berengian et al. (27). Further, a positive reaction of this protein with IT-1 and IT-4 suggests the similarity of this $16-\mathrm{kDa}$ protein with the already reported 16-kDa hsp antigen.

Hsp 16.3 has been found to occur as an oligomer consisting of trimers (nine-subunit complex) and was found to play a role as a chaperone based on its activity in preventing thermal denaturation of alcohol dehydrogenase (28) and aggregation of citrate synthase (29) in vitro. In our study too, the antigen seems to exist in two different molecular forms, as two peaks of different retention times were obtained from the purified antigen preparation when analyzed by HPLC through a C18 reverse-phase column. However, when the two peaks were separately analyzed by SDS-PAGE, both contained only the 16-kDa protein, which shows that the protein exists in different oligomeric forms.

Thus, methods have been developed for purification of three diagnostically relevant antigens, in sufficient quantity and purity. Thethreepurified proteins individually and in combination will be evaluated for serodiagnosis of tuberculosis.

\section{ACKNOWLEDGMENTS}

Financial support provided by the Indo-U.S. Vaccine Action Programme, through the Department of Biotechnology, Government of India, is gratefully acknowledged. We acknowledge with thanks the laboratory facilities made available by the collaborator, Professor Patrick J . Brennan (Colorado State University, CO). Ms. K. R. Uma Devi is therecipient of aJ unior Research Fellowship from theDepartment of Biotechnology, Government of India. Mr. B. Ramalingam is the recipient of a Senior Research Fellowship from the Council of Scientific and Industrial Research (New Delhi, India). The authors are grateful to the WHO Recombinant Antigen Bank for providing r38kDa antigen for reference. The authors are also thankful to Dr. K. N. Sulochana, Department of Biochemistry, Vision Research Foundation (Chennai, India), and Dr. R. J ayakumar, Department of BioOrganic Chemistry, Central Leather Research Institute (Chennai, India), for providing the facilities for HPLC and CD, respectively.

\section{REFERENCES}

1. Enarson, D., and Murray, J . (1996) Global epidemiology of tuberculosis, in "Tuberculosis" (Rom, W. N., and Garay, S., Eds.), pp. 57-75, Little, Brown, and Co.

2. Raviglione, M. C., Snider, D. J., and Kochi, A. (1995) Global epidemiology of tuberculosis. Morbidity and mortality of a worldwide epidemic. J AMA 273, 220-226.

3. World Health Organization (1998) Antituberculosis drug resistance worldwide. 73, 249-256.

4. Chan, E. D., Heifets, L., and Iseman, M. D. (2000) I mmunologic 
diagnosis of tuberculosis: A review. Tuberc. Lung Dis. 80, 131-140.

5. Daniel, T., and Debanne, S. (1987) Theserodiagnosis of tuberculosis and other mycobacterial diseases by enzyme-linked immunosorbent assay. Am. Rev. Respir. Dis. 135, 1137-1151.

6. Laemmli, U. K. (1970) Cleavage of structural proteins during the assembly of the head of bacteriophage T4. Nature 227, 680-685.

7. Towbin, H., Staehelin, T., and Gordon, J . (1979) Electrophoretic transfer of proteins from polyacrylamide gels to nitrocellulose sheets: Procedure and some applications. Proc. Natl. Acad. Sci. USA 76, 4350-4354.

8. O'Farrell, P. H. (1975) High-resolution two-dimensional electrophoresis of proteins. J . Biol. Chem. 250, 4007- 4021.

9. Daniel, T. M., and Anderson, P. A. (1978) The isolation by immunosorbent affinity chromatography and physicochemical characterization of Mycobacterium tuberculosis antigen 5. Am. Rev. Respir. Dis. 117, 533-539.

10. Young, D., Kent, L., Rees, A., Lamb, J ., and Ivanyi, J . (1986) I mmunological activity of a 38-kilodalton protein purified from Mycobacterium tubercul osis. I nfect. I mmun. 54, 177- 183.

11. Kadival, G. V., and Chaparas, D. (1987) Production, characterization and species specificity of five monoclonal antibodies to Mycobacterium tuberculosis. J . Clin. Microbiol. 25, 76-80.

12. Espitia, C., Cervera, I., Gonzalez, R., and Mancilla, R. (1989) A 38-kD Mycobacterium tubercul osis antigen associated with infection. Its isolation and serologic evaluation. Clin. Exp. Immunol. 77, 373-377.

13. Singh, M., Andersen, A. B., McCarthy, J. E. G., Rohde, M., Schutte, H., Sanders, E., and Timmis, K. N. (1992) The Mycobacterium tuberculosis 38kDa antigen: Over expression of the gene in Escherichia coli and purification and characterisation of the recombinant product. Gene 117, 53-60.

14. Bassey, E. O. E., Catty, D., Kumararatne, D. S., and Raykundalia, C. (1996) Candidateantigens for improved serodiagnosis of tuberculosis. Tuberc. Lung Dis. 77, 136- 145.

15. J ackett, P. S., Graham, H. P., Harsh, V. B., Mistry, A., Young, B. D., and I vanyi, J . (1988) Specificity of antibodies to immunodominant mycobacterial antigens in pulmonary tuberculosis. J . Clin. Microbiol. 26, 2313-2318.

16. Bothamley, G. H., Rudd, R., Festenstein, F., and I vanyi, J . (1992) Clinical value of themeasurement of Mycobacterium tubercul osis specific antibody in pulmonary tuberculosis. Thorax 47, 270-275.

17. Nagai, S., Wiker, H. G., Harboe, M., and Kinomoto, M. (1991) I solation and partial characterization of major protein antigens in theculture fluid of Mycobacterium tubercul osis. I nfect. I mmun. 59, 372-382.

18. Thole, J. E. R., Schoningh, R., J anson, A. A. M., Garbe, T., Cornelisse, Y. E., Clark-Curtiss, J . E., Kolk, A. H. J ., Ottenhoff, T. H. M., De Vries, R. R. P., and Abou-Zeid, C. (1992) Molecular and immunological analysis of a fibronectin-binding protein antigen secreted by Mycobacterium leprae. Mol. Microbiol. 6, 153163.

19. Wiker, H. G., and Harboe, M. (1992) The antigen 85 complex: A major secretion product of Mycobacterium tuberculosis. Microbiol. Rev. 56, 648-661.

20. Daniel, T. M., and Ferguson, L. E. (1970) Purification and characterization of two proteins from culture filtrates of Mycobacterium tubercul osis H37Ra strain. I nfect. I mmun. 1, 164- 168.

21. Lim, J . H., Park, J . K., J o, E. K., Song, C. H., Dullei, M., Song, Y. J ., and Kim, H. J . (1999) Purification and immunoreactivity of three components from the 30/32-kilodalton antigen 85 complex in Mycobacterium tuberculosis. Infect. Immun. 67, 61876190.

22. Van Vooren, J. P., Drowart, A., de Cock, M., van Onckelen, M. H., D'H oop, M. H., Yernault, J . C., Valcke, C., and Huygen, K. (1991) H umoral immuneresponse of tuberculous patients against the three components of the Mycobacterium bovis BCG 85 complex separated by isoelectric focusing. J. Clin. Microbiol. 29, 2348-2350.

23. Drowart, A., Launois, P., De Cock, J ., Yernault, J ., and Van Vooren, J. P. (1991) An isoelectric focusing method for the study of the humoral response against the antigen 85 complex of Mycobacterium bovis BCG in the different forms of leprosy. J . I mmunol. Methods 145, 223-228.

24. Lee, B. Y., Hefta, S. A., and Brennan, P.J . (1992) Characterization of the major membrane protein of virulent Mycobacterium tuberculosis. Infect. I mmun. 60, 2066-2074.

25. Garbe, T. R., Hibler, N. S., and Deretic, V. (1999) Response to reactive nitrogen intermediates in Mycobacterium tuberculosis: Induction of the 16-kilodalton $\alpha$-crystallin homolog by exposure to nitric oxide donors. I nfect. I mmun. 67, 460-465.

26. Verbon, A., Hartskeerl, R. A., Schuitema, A., Kolk, A. H.J ., Young, D. B., and Lathigra, R. (1992) The 14,000 molecular weight antigen of Mycobacterium tuberculosis is related to the $\alpha$-crystallin family of low-molecular weight heat shock proteins. J . Bacteriol . 174, 1352- 1359.

27. Berengian, A. R., Parfenova, M., and Mchaourab, H. S. (1999) Site-directed spin labeling study of subunit interactions in the $\alpha$-crystallin domain of small heat-shock proteins-Comparison of the oligomer symmetry in $\alpha$-crystallin, HSP 27 and HSP 16.3. J . Biol. Chem. 274, 6305-6314.

28. Yuan, Y., Crane, D. D., Simpson, R. M., Zhu, Y., Hickey, M. J ., Sherman, D. R., and Barry, C. E. (1998) The 16 kDa $\alpha$-crystallin (Acr) protein of Mycobacterium tubercul osis is required for growth in macrophages. Proc. Natl. Acad. Sci. USA 95, 9578- 9583.

29. Chang, Z., Primm, T. P., J akana, J ., Lee, I. H., Serysheval, I., Chiu, W., Gilbert, H. F., and Quiocho, F. A. (1996) Mycobacterium tuberculosis $16 \mathrm{kDa}$ antigen (Hsp16.3) functions as an oligomeric structurein vitroto suppress thermal aggregation. J . Biol. Chem. 271, 7218-7223. 